\title{
Quality Enhancement through Hybrid Skill Management Concept for Multi-Type Aircraft Fleet
}

\author{
HAFIZ TAHIR MAHMOOD*, IHSAN AHMED BHATTI*, AND TASWEER HUSSAIN* \\ RECEIVED ON 19.01.2017 ACCEPTED ON 13.11.2017
}

\begin{abstract}
Scarcity of resources is becoming a universal challenge for the world community. Conservation of resources could only be possible if the quality concept of waste reduction is introduced and implemented in utilization of existing resources. Out of the countless dimensions of resource conservation, this research focuses on formulation of maintenance model through human resource conservation and its optimum utilization in aviation industry. The research work remained converged to the basic managerial aspect of skill management for Multi-type rating certification. The paper introduces a new concept with enhanced managerial quality for the first line operations of Multi-type aircraft fleet. The concept has introduced synergy concept for human resource utilization to reduce the requirement of per aircraft technicians and engineers. The research has identified that quality enhancement in three major areas namely hiring process, skill development process and maintenance practices have major role to play for optimum utilization of human resource assets. The results finally achieved show remarkable reduction in overall cost effect even though with enhanced quality.
\end{abstract}

Key Words: Aviation Industry, Multi-Aircraft, Maintenance Management, Managerial Quality, Maintenance Model, First Line Operations.

\section{INTRODUCTION}

$\mathrm{T}$ he Corporation is all about making profits. Like many other industries, aviation industry also looks for growth of industry and increase in the profit margins. To achieve this, the management executives exercise various strategies for departmental improvements to enhance efficiency. The effectiveness of strategy is measured on the basis of variation in revenue generation. In the field of aviation maintenance management, regardless of the type of fleet operations, commercial or charter, the executives seeking high profits, primarily focus on improvement in the quality of aircraft outfield maintenance management. This effective outfield maintenance is possible through better management of human resource. Industry of aeronautics has provided its estimates (with regard to cost related to maintenance activities), whereby they have highlighted that out of overall direct operating costs, maintenance activities have an average share of $10-20 \%$ [1]. However, as per their analysis, this depends on fleet size age and usage. International Civil Aviation Organization has however

Authors E-Mail: (tahir.mahmood@ceme.nust.edu.pk, ihsaan_99@yahoo.com, tasweer@ceme.nust.edu.pk)

* Department of Engineering Management, College of Electrical \& Mechanical Engineering, National University of Science \& Technology, Islamabad.

This is an open access article published by Mehran University Research Journal of Engineering and Technology, Jamshoro under the CC by 4.0 International License. 
provided little different estimates. As per their research, average figure is $11 \%$ but this average includes individual figures up to the maximum value of $25 \%$ [1]. These operational costs of aviation business get further escalated due to increasing competitive environment which stipulates the airline managements to seek permanent improvements in their management practice at both the planning and operating levels.

Schedule punctuality is the prime focus of aviation business and this target could only be achieved if all dimensions of management are in harmony with each other. There are a number of performance indicators in aviation industry with regards to its operations. One of the most important indicator for outfield maintenance operations is the TAT (Turn Around Time). In order to achieve the optimal TAT, the systems and actions must be well coordinated. The prioritization of actions with effective communication is the key factor for generating wellcoordinated actions at all levels of maintenance. Aviation maintenance practices involve maintenance activities at three different levels. These levels are on the basis of maintenance actions and time limitations; these levels are:

\section{$1.1 \quad$ Organizational Level}

O-Level (Organizational Level) or $1^{\text {st }}$ line maintenance is also known as line operations where inspections are performed at three different stages of flight including before flight maintenance (pre-flight), between two flights of the day (thru-flight) and at the end of day flying or after landing of last flight of the day (post-flight) inspections along with minor maintenance that includes replacement of LRUs (Line Replacement Units) and operational checks etc. Line maintenance is generally limited to one to three hours of maintenance time.

\subsection{Intermediate Level}

I-Level (Intermediate Level) or $2^{\text {nd }}$ line maintenance comprises of the periodic inspections such as ' $A$ ' and ' $B$ ' checks. 'A' checks are the one which involve minor periodic inspection checks of aircraft. These type of checks result in grounding time of aircraft of up to two days. ' $\mathrm{B}$ ' type checks are more detailed checks and require three to five days of grounding time depending on the aircraft type.

\subsection{Depot Level}

D-Level (Depot Level) includes $3^{\text {rd }}$ and $4^{\text {th }}$ line overhauling maintenance for component and aircraft respectively. Components are removed for periodic inspections and are sent to overhauling shops for inspection/ maintenance. This maintenance requires variable time depending on the type of components; however, this maintenance time does not hamper the fleet serviceability because the aircraft are serviced with replacement units. On the other hand, the aircraft overhauling may span over 20 or more days of aircraft grounding depending on the size of the aircraft. These inspections are generally designated as ' $\mathrm{C}$ ' or ' $\mathrm{D}$ ' checks.

The $1^{\text {st }}$ line maintenance management is considered a key factor for quality and efficiency of airline operations. Line maintenance operations require fast-paced yet safetyconscious actions that demands highest level of professionalism and time-bound decision making skills.

\section{LITERATURE REVIEW}

A number of publications address aviation maintenance management specially, in the Operations Research literature. Papakostas et. al. [1] the research work provides a planning methodology to manage short-term issues of first line aviation maintenance. It includes reduced turnaround time, better staggering plan for aircraft grounding 
for scheduled maintenance and health monitoring of aircraft fleet. The research work has proven its validity and affectivity through experimentation. Yan et. al. [2] presented eight successful maintenance management models that also include technical human resource management. The research work defines how the certifications requirements be managed to utilize the available resource in most effective manner using a mathematical model. Moudani et. al. [3], the researchers focused on the issues which are primarily connected with maintenance of fleet. The paper proposes a scheme/ mechanism which may be considered as the basis for the on-line decision support system within airlines. Gramopadhye, and Drury [4] provides the rationale for research work that gives an overview of the domain, both of which may not be familiar to human factors and ergonomics practitioners. As per their research, 75\% of the time the accidents or incidents are attributed to 'pilot error' or 'human error', however, a recent study in the United States found that $18 \%$ of all accidents indicate maintenance factors as a contributing agent. Kilpia, and Vepsalainen [5], the authors showed another dimension of first line aircraft management whereby their strategy to minimize aircraft grounding time due to non-availability of spares defines that a nexus among airlines for mutual utilization of spares inventory is a way to win-win situation for all the stakeholders. Authors have proved this strategy as the most feasible among the inventory management practices. Hoffman [6] highlights the ways by which the aircraft utility could be maximized with optimal life consumption. Masud et. al. [7], the authors encompass their research to the military weapon system management and provided the survivability analysis for effective utilization of aircraft in war scenario. Adel and Chris [8] had talked about the inventory management technique and have highlighted that MRP phenomenon has edge over the re-order point philosophy for aircraft fleet. Sodhi [9], author has indicated the complexity attached to the aviation industry by comparing aviation industry with the electronic industry. The author has claimed that aviation industry is a risky one due to product complexity like in case of electronic industry we have the risk of short product life cycle and demand uncertainty. Lee et. al. [10] the authors talked about the handling of aircraft spare parts allocation issue through a framework which actually combines MOEA (Multi-Objective Evolutionary Algorithm) through MOCBA (MultiObjective Computing Budget Allocation) method to achieve multiple objectives with regard to simulation optimization problem. The study covered the features of huge search space, multi-objective, and high variability. Behrens [11] has argued that the aviation industry like many other industries seems to be suffering as the goods are being pushed through to manufacture in the schedule of overall production that may well not be aligned with the actual customer requirements at the time of final product delivery. Though this situation is not so common in aviation manufacturing business because of standardization requirement, however has quite an impact in other manufacturing lines. This situation could surely have effect on quality of the overall system as well. Stojkovi et. al. [12] provides an operational management scheme for crew detailing on variety of itineraries in order to achieve efficient and most acceptable solution for dayto-day issues. Sriram and Ali [13] provided the most cost effective model for aircraft detailing by using heuristic approach and keeping in view the maintenance schedule requirements. Liang et. al. [14] recommended the solution in preventing human errors due to maintenance actions. The research provided the on-line maintenance assistance program that reduces the possibilities of human factor occurrences, subsequently resulting in enhanced reliability and safety of maintenance operations. Hsu et. al. [15], the authors provided the critical analysis of SMS (Safety Management System) in order to plug all the loop holes in the system. The study is especially beneficial for

Mehran University Research Journal of Engineering \& Technology, Volume 37, No. 3, July, 2018 [p-ISSN: 0254-7821, e-ISSN: 2413-7219] 
safety management and error prevention at aircraft fleet. Janic [16], the research provided the means of assessing risk and safety in civil aviation. The study proposes the mathematical methodology for quantifying the risk and safety that enables the managers to foresee the anticipated threats to aircraft safety. Sarac [17], an operational aircraft maintenance routing problem formulation is addressed. Here the author has argued that maintenance resource availability constraints has a huge impact on operational aircraft maintenance routing problems. He went on to claim that use of a branch-andprice algorithm could be utilized on aiming at minimizing the number of the aircraft's unused legal flying hours. The problem formulation includes maintenance resource availability constraints, where a branch-and-price algorithm is used for exploring the efficiency of the maintenance routing solutions. Tiwari [18] has highlighted the importance of concept of quality maintenance through better resource management and has declared industry consolidation and partnership. Soon et. al. [19], authors have pointed out the importance of effective supply chain management in ensuring effective maintenance. They believed thatsupply chain ûexibility is as good in maintenance as in any other field. This is an ability to reconûgure the supply chain and alter product or component supply of product as per customer demand to achieve optimal results. Finally, Pleumpirom and Amornsawadwatana [20] authors have highlighted that the multi objective optimization though goal programming has lot of importance for organizations maintaining the aircraft. They have concluded in their research work that this approach of aircraft maintenance organizations not only helps in reducing costs, but useful for reducing aircraft ground time along with improving quality.

\section{MAERIALS AND METHOD}

The research work has been conducted through structured interviews and data collection through questionnaire from the personnel working in aviation industry itself. Prime source of data collection is structured interview, however, for identification of quality enhancement factors, questionnaire was floated to $\mathbf{1 2 3}$ personnel related to aviation field. 87 of them responded to the simple questionnaire. The questionnaire comprised of both open ended and close ended questions. For close ended questions, five point lickert scale (Strongly Agree - Agree - Neutral - Disagree - Strongly Disagree) was used. The research work is a combination of quantitative (through close ended question) as well as qualitative work (Structured interviews and Open ended question).

This paper presents an efficient maintenance management model for multi-aircraft charter fleet through introduction of quality aspects of optimal resources utilization. The scope of research is limited to the $1^{\text {st }}$ line maintenance operations of an aircraft fleet with five different types of aircraft - one of each type, under a single managerial setup with unscheduled flying commitments. During the research special emphasis is laid on the skill management for various technical trades in order to make the human resource lean yet efficient, backed up with more organized training of maintenance crew, computerized planning, scheduling and documentation of aircraft operations and improved logistics management of different aircraft spares.

\subsection{Technical Skill Management}

Humans are the best tools in any organization. The effectiveness of this tool is judged through the capabilities and skillfulness. In order to ensure optimum safety in aviation business, the aviation regulatory authorities have laid down strict certification regulations for all facets of aviation services including technical manpower. For engineering and maintenance setups certifications are required for each level and in particular skill or trade. In order to maintain the aviation industry,

Mehran University Research Journal of Engineering \& Technology, Volume 37, No. 3, July, 2018 [p-ISSN: 0254-7821, e-ISSN: 2413-7219] 
aircraft maintenance demands high level of professional, training skills at different levels. This may also include different certification and different instruments.In order to maintain the aircraft fleet, maintenance crew is usually separated into different groups, which are responsible for specific maintenance plans and tasks [2]. In this paper a revised skill management model has been presented that introduces following concepts for technical work force management:

(i) Dual trade for licensed cadre

(ii) Single trade for non-licensed Cadre

In the research work, existing setup was analyzed first and thereafter on the basis of inputs from various aviation setups and structured interviews from the people actually working in the field or managing aviation business, a revised model is formulated followed by the result comparison and effectiveness of revised model.

\subsection{Existing Setup}

Firstly, the existing skill management setup is analyzed. Most of the aviation corporations in Pakistan still maintain six-technical trade setups that include Airframe, Engine, Electrical, Instrument, Radio and Radar trades. Each trade further comprises of licensed and non-licensed manpower.
In the existing setup each trade is responsible for rectification of respective trade related discrepancies; hence the working shift includes technical manpower from each trade and from each cadre. Fig. 1 gives the detailed overview of existing skill management setup for maintenance practices being followed in first line aircraft maintenance setups.

\subsection{Analysis of Existing Setup}

In order to analyze the existing setup, first of all variables were identified and then their inter-relationship was formulated. After formulating the relationship equation, the results were graphically promulgated for a specific situation as mentioned in subsequent paragraphs. The variables and their descriptions are as follows:

X Number of types of aircraft

1 'Licensed' designator

nl 'Non-licensed' designator

$\mathrm{S}_{1} \quad$ Strength of licensed person-power

$\mathrm{S}_{\mathrm{nl}} \quad$ Strength of non-licensed person-power

$\mathrm{N}_{\mathrm{s}} \quad$ No. of working shift

$\mathrm{L}_{\mathrm{p}} \quad$ Leave/vacation percentage as per organizational policy

$\mathrm{T}_{\mathrm{r}} \quad$ No. of technical trades

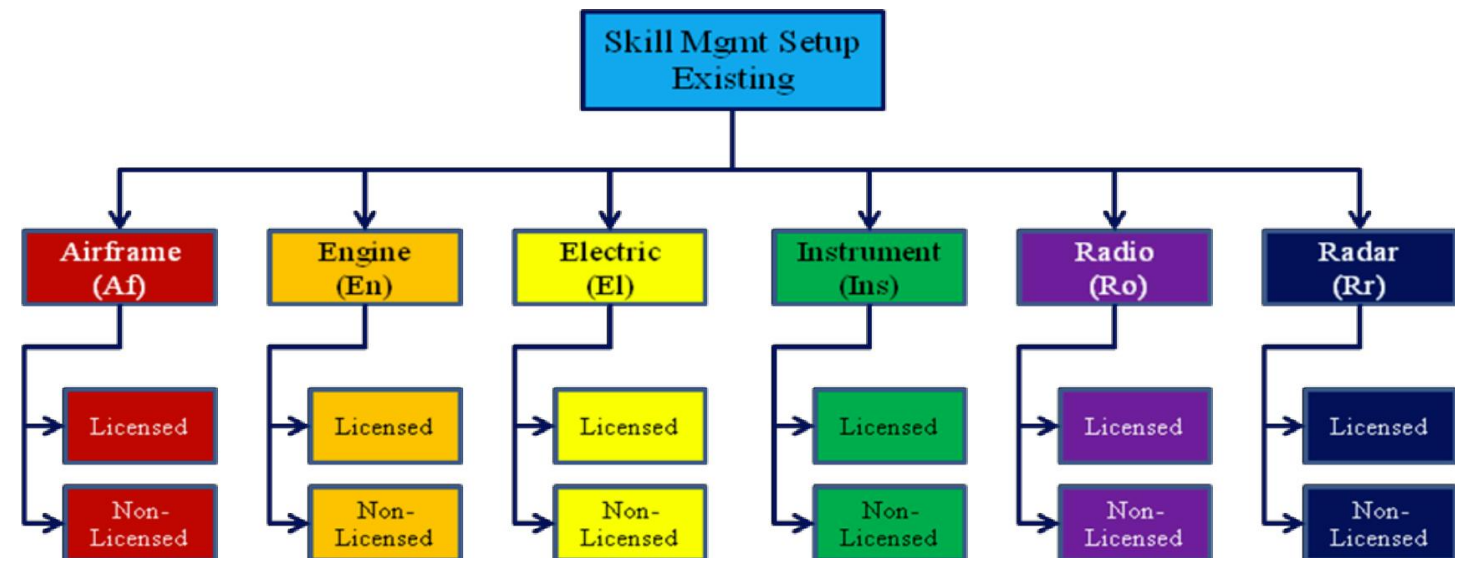

FIG. 1. SKILL HIERARCHY IN EXISTING SETUP 
h No. of working hours per working shift per person

$\mathrm{W}_{1} \quad$ Annual wage of a licensed person

$\mathrm{W}_{\mathrm{nl}} \quad$ Annual wage of a non-licensed person

Trade-wise strength of technical staff per aircraft per shift $=\left(S_{1}+S_{n l}\right)$

Working Strength of technical staff per aircraft per shift $=\mathrm{T}_{\mathrm{r}} *\left(\mathrm{~S}_{1}+\mathrm{S}_{\mathrm{n}}\right)$

Working strength of technical staff per shift $=\mathrm{X}^{*} \mathrm{~T}_{\mathrm{r}}{ }^{*}$ $\left(\mathrm{S}_{1}+\mathrm{S}_{\mathrm{nl}}\right)$

Total number of personnel required for first line operations including personnel on leave/vacations

$=\mathrm{N}_{\mathrm{s}} * \mathrm{X} * \mathrm{~T}_{\mathrm{r}} *\left(\mathrm{~S}_{1}+\mathrm{S}_{\mathrm{nl}}\right) *\left(1+\mathrm{L}_{\mathrm{p}}\right)$

In the existing setup, a minimum of five tradesmen from each trade are included in each working shift, out of these five, one to two is (are) essentially a licensed engineer(s) and rest three or four are generally non-licensed technicians. Collectively, the working shift comprises of minimum of 30 personnel for one type of aircraft, whereas for the scenario under research in which five different types of aircraft are considered, the shift strength reaches to more than hundred personnel. Fig. 2 represents the person-power relationship (human resource relationship) with respect to aircraft types in the existing setup as per Scenario-1 and Scenario-2.

Scenario-1: Lets suppose a scenario where $\mathrm{N}_{\mathrm{s}}=4$ (3 working shifts and 1 on night-off), $\mathrm{L}_{\mathrm{p}}=10 \%, \mathrm{~T}_{\mathrm{r}}=6$ and per trade person-power requirement per shift is minimum of five i.e. one licensed and four non-licensed personnel per trade, Table 1 shows the mathematical relationship between ' $\mathrm{X}$ ' i.e. total types of aircraft and the total person-power requirement:

Fig. 2 represents the person-power relationship with respect to aircraft types in the existing setup with licensed and non-licensed workers details shown separately.

The graph shows a linear relationship between ' $X$ ' and ' $\left(\mathrm{S}_{1}+\mathrm{S}_{\mathrm{nl}}\right)$ ' i.e requirement of human resource increases with increase in types of aircraft in a linear fashion. Now, if the number of personnel is converted to the annual cost estimation, the following relationship is formulated:

Cost of HR $=\mathrm{N}_{\mathrm{s}} * \mathrm{X} * \mathrm{~T}_{\mathrm{r}} *\left(\mathrm{~W}_{1} * \mathrm{~S}_{1}+\mathrm{W}_{\mathrm{nl}} * \mathrm{~S}_{\mathrm{nl}}\right) *\left(1+\mathrm{L}_{\mathrm{p}}\right)$

TABLE 1. TECHNICAL HR CADRES VS AIRCRAFT TYPES IN EXISTING SETUP

\begin{tabular}{|c|c|c|c|c|}
\hline \multicolumn{5}{|c|}{ Licensed Engineers (No) } \\
\hline Aircraft Type(s) & Required Strength/ Shift & Required Strength/Day & Off-Duty Personnel (10\%) & Total Requirement \\
\hline 1 & 6 & 24 & 2 & 26 \\
\hline 2 & 12 & 48 & 5 & 53 \\
\hline 3 & 18 & 72 & 7 & 79 \\
\hline 4 & 24 & 96 & 10 & 106 \\
\hline 5 & 30 & 120 & 12 & 132 \\
\hline \multicolumn{5}{|c|}{ Non-Licensed Technicians (No) } \\
\hline 1 & 24 & 96 & 10 & 106 \\
\hline 2 & 48 & 192 & 19 & 211 \\
\hline 3 & 72 & 288 & 29 & 317 \\
\hline 4 & 96 & 384 & 38 & 422 \\
\hline 5 & 120 & 480 & 48 & 528 \\
\hline
\end{tabular}


Assuming the per annum salaries of licensed and nonlicensed persons as $\$ 75000$ and $\$ 25000$, respectively, Table 2 shows the cost impact due to number of personnel working in existing skill management or maintenance setup.

The combined cost of personnel for both licensed engineers and non-licensed technicians also shows a linear trend against the scale of aircraft types. The cost impact is exhibited in bar-charts vis-à-vis the number of aircraft types as shown in Fig. 3.

\subsection{Revised Model}

In order to conserve HR assets and to optimize their utilization, the setup needs to be revised in a way that the

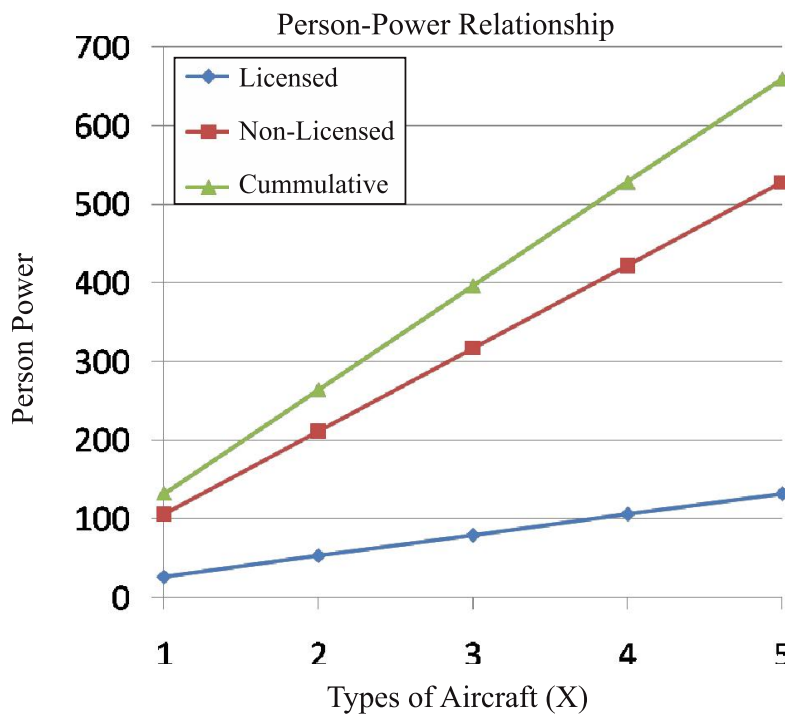

FIG. 2. PERSON-POWER RELATIONSHIP VS AIRCRAFT TYPES IN EXISTING SETUP new model does not hamper the technical as well as the managerial operations of the first-line aviation management. In revised model, the setup of technical human resource has been changed from six trades to two trades for licensed cadre and single trade for non-licensed cadre. Fig. 4 gives the detailed overview of revised skill management setup for maintenance practices in first line aircraft maintenance setups.

Through the inputs received during the research, with the introduction of new concept of hybrid skill management for non-licensed cadre, following relationship was formulated for desired number of human resource:

In revised model, the following relationship Equation (3) defines the total No. of personnel required for first line operations including personnel on leave/vacations, are:

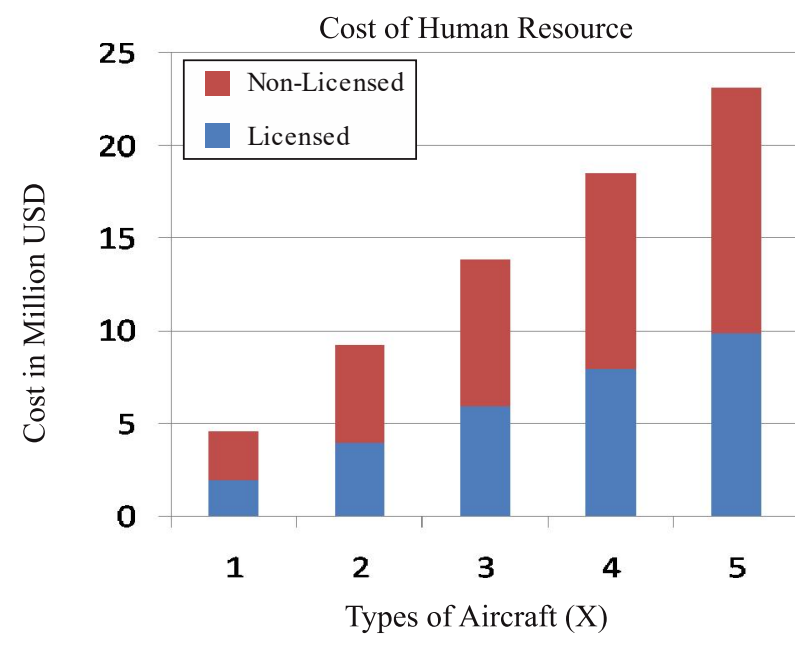

FIG. 3. COST OF PERSONNEL RELATIONSHIP VS AIRCRAFT TYPESIN EXISTING SETUP

TABLE 2. COST OF PERSONNEL IN EXISTING SETUP

\begin{tabular}{|c|c|c|c|}
\hline \multicolumn{3}{|c|}{ Cost of Personnel (In Millions of USD) } \\
\hline Aircraft Type(s) & Cost of Licensed Engineers & Cost of Non-Licensed Technicians & Cumulative Cost Effect \\
\hline 1 & 1.95 & 2.65 & 4.6 \\
\hline 2 & 3.975 & 5.275 & 9.25 \\
\hline 3 & 5.925 & 7.925 & 13.85 \\
\hline 4 & 7.95 & 10.55 & 18.5 \\
\hline 5 & 9.9 & 13.2 & 23.1 \\
\hline
\end{tabular}

Mehran University Research Journal of Engineering \& Technology, Volume 37, No. 3, July, 2018 [p-ISSN: 0254-7821, e-ISSN: 2413-7219] 
$=\mathrm{N}_{\mathrm{s}} * \mathrm{X} *\left(\mathrm{~T}_{\mathrm{r}} * \mathrm{~S}_{1}+\mathrm{S}_{\mathrm{nl}}\right) *\left(1+\mathrm{L}_{\mathrm{p}}\right)$

In Equation (3), it can be seen that factor of trades is only multiplied with strength of licensed personnel because in the revised setup there are two specialties for the licensed engineers whereas no such trade factor is multiplied with the strength of non-licensed technicians because there is only one trade for the non-licensed cadre. The scope of research remained limited to the scenario where each licensed engineer is certified for one specialty of a particular type of aircraft. Under this scenario the requisite number of licensed engineers can be defined through the simple relationship shown in Equation (4).

$\mathrm{S}_{1}=\mathrm{X} * \mathrm{~T}_{\mathrm{r}}$

Research survey also reveals that licensed engineers with one certification out of the two specialties, for a specific aircraft type, justifies the job requirements in best possible manner, however, if we assume a scenario where the licensed engineers can get maximum of three type rating certifications, then Equations (5-6) identify the minimum requirement of licensed engineers with respect to the number of aircraft types $(\mathrm{X})$ :

Requirement of $\mathrm{S}_{1}=\mathrm{T}_{\mathrm{r}}$ for $1 \leq \mathrm{X} \leq 3$

Requirement of $\mathrm{S}_{1}=2\left(\mathrm{~T}_{\mathrm{r}}\right)$ for $4 \leq \mathrm{X} \leq 6$
On the other hand, as there is no segregation of trades in non-licensed cadre therefore the rule of synergy is applied to optimize the requirement of non-licensed technicians. While keeping the ratio between the licensed engineer and the non-licensed technician as same i.e. 1:4 for one aircraft type i.e. $X=1$, the research puts forward Equation (7) for identifying the requirement of non-licensed technicians vis-à-vis the number of aircraft $(\mathrm{X})$ :

Requirement of $\mathrm{S}_{\mathrm{nl}}=\mathrm{X} * 8 /(“ \mathrm{X})$

Scenario-2: Let's take the example of similar scenario as mentioned earlier where $\mathrm{N}_{\mathrm{s}}=4$ i.e. 3 working shifts and 1 on night-off), $\mathrm{L}_{\mathrm{p}}=10 \%$, No. of trades have now reduced from six to one for non-licensed technicians and from six to two for licensed engineers hence $T_{r}=2$. The per trade person-power requirement for licensed engineers per shift is minimum of two i.e. one licensed engineer from each specialty and requirement of non-licensed personnel as per Equation (7), then Table 3 shows the mathematical relationship between ' $\mathrm{X}$ ' i.e. total types of aircraft and the total person-power requirement.

Fig 5 represents the person-power relationship with respect to aircraft types in the revised setup with licensed and non-licensed workers' details shown separately. Fig. 6, the same scale of Fig. 6 is enlarged for better understanding.

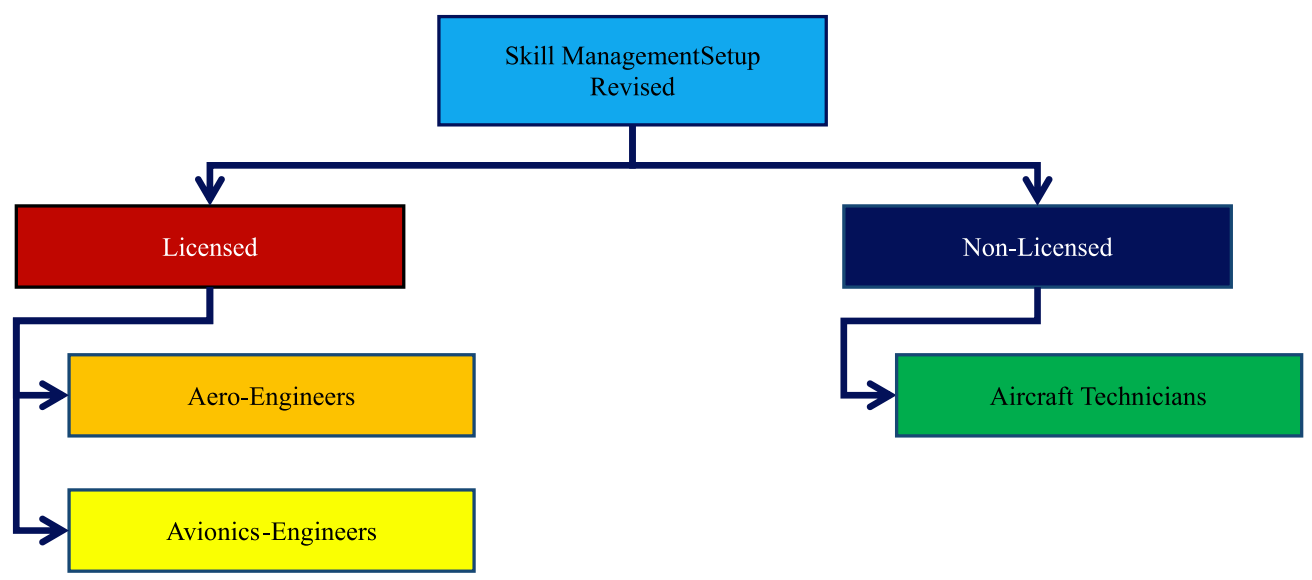

FIG. 4. SKILL HIERARCHY IN REVISED MODEL 
Now if the vertical scale for Fig. 5 is enlarged (for better understanding), following can be seen:

The relationship between aircraft types and the number of licensed engineers is in linear proportion whereas due to synergy concept the relation between aircraft types and the non-licensed is curved i.e as the types of aircraft increases, the per aircraft requirement of non-licensed technicians decreases as per the relationship put forward through this research and is mentioned at Equation (7).

Now if the cost impact of personnel is analyzed as per the revised set assuming the same cost of personnel for each cadre as highlighted in Scenario-1, Table 4 will represent the cost figures for each cadre (as per types of aircraft) independently and cumulatively:

Graphically the Data is represented as follows:

The combined cost of personnel for both licensed engineers and non-licensed technicians also shows a linear trend against the scale of aircraft types. The cost impact for revised model is exhibited in bar-charts vis-àvis the number of aircraft types as shown in Fig. 7.

\section{RESULTS AND DISCUSSION}

For comparison purposes, both the scenarios are analyzed for reduced number of human resource and the percent reduction in cost from Scenario-1 to Scenario-2. Table 5 shows the result comparisons for both existing and revised model (defined as Scenario-1 and Scenario-2 in this paper) respectively. Results thus achieved as shown in Table 5 clearly show huge reduction in overall

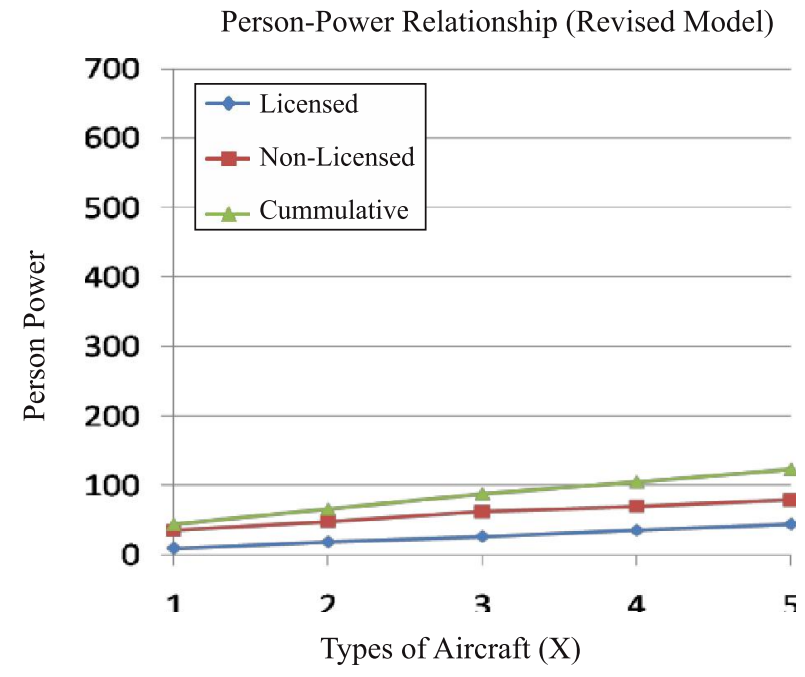

FIG. 5. PERSON-POWER RELATIONSHIP VS AIRCRAFT TYPES IN REVISED MODEL

TABLE 3. TECHNICAL HR CADRES VS AIRCRAFT TYPES IN REVISED MODEL

\begin{tabular}{|c|c|c|c|c|}
\hline \multicolumn{5}{|c|}{ Licensed Engineers (No) } \\
\hline Aircraft Type(s) & Required Strength/ Shift & Required Strength/Day & Off-Duty Personnel (10\%) & Total Requirement \\
\hline 1 & 2 & 8 & 1 & 9 \\
\hline 2 & 4 & 16 & 2 & 18 \\
\hline 3 & 6 & 24 & 2 & 26 \\
\hline 4 & 8 & 32 & 3 & 45 \\
\hline 5 & 10 & 40 & 4 & 35 \\
\hline 1 & 8 & Non-Licensed Technicians (No) & 3 & 48 \\
\hline 2 & 11 & 32 & 4 & 6 \\
\hline 3 & 14 & 44 & 6 & 70 \\
\hline 4 & 16 & 56 & 64 & 7 \\
\hline
\end{tabular}

Mehran University Research Journal of Engineering \& Technology, Volume 37, No. 3, July, 2018 [p-ISSN: 0254-7821, e-ISSN: 2413-7219] 
cost effect as shown in change column for different types of aircraft.

From the comparison we can deduce that as the number of aircraft types increases the percentage change in human resource also increases i.e. per aircraft requirement of human resource has reduced reason due to the synergy concept for non-licensed cadre. On the other hand, as the types of aircraft increases, the percentage change in cost effect reduces which is because of the more requirement of licensed engineers that has a direct relationship with the number of aircraft types.

On the basis of structured interviews, a number of quality enhancement factors were identified. On the

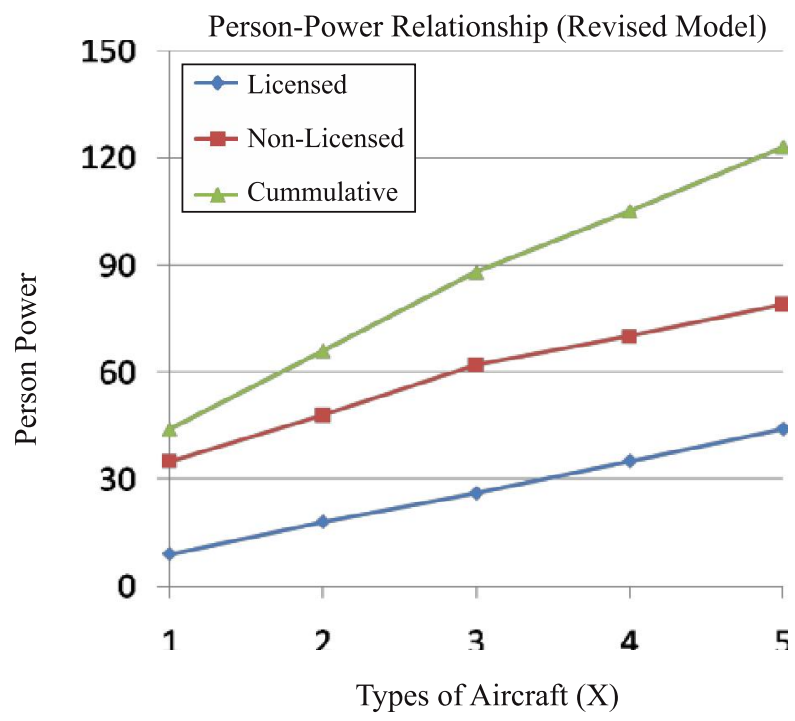

FIG. 6. PERSON-POWER RELATIONSHIP VS AIRCRAFT TYPES IN REVISED MODEL (WITH ENLARGED SCALE) basis of this raw data, questionnaire was floated among engineers/technicians working at different cadres in the aviation industry to find out major quality enhancement factors. Questionnaire was responded by 87 people from the first line setup of aircraft maintenance setup of different commercial and military setup personnel. The results thus achieved showed following three factors as the major factors (as identified by respondents) as they contributed for $\mathbf{8 0 . 4 \%}$ out of the overall results.

Table 6 shows the quantitative results achieved from questionnaire for highlighting the number and percentage of respondents identifying the most critical and significant area for enhancing overall quality standards.

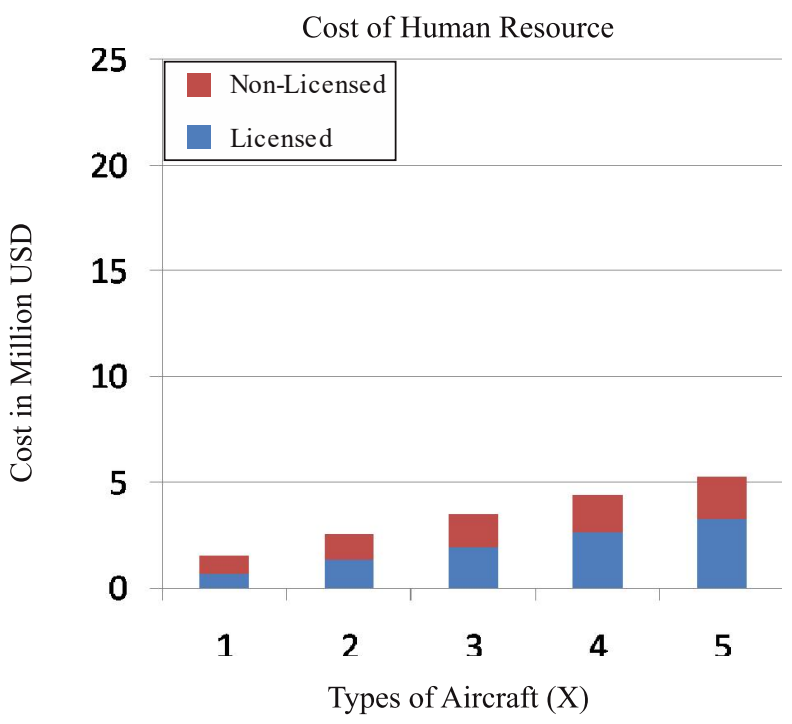

FIG. 7. COST OF PERSONNEL RELATIONSHIP VS AIRCRAFT TYPES IN REVISED MODEL

TABLE 4. COST OF PERSONNEL IN REVISED MODEL

\begin{tabular}{|c|c|c|c|}
\hline \multicolumn{5}{|c|}{ Cost of Personnel (In Millions of USD) } \\
\hline Aircraft Type(s) & Cost of Licensed Engineers & Cost of Non-Licensed Technicians & Cumulative Cost Effect \\
\hline 1 & 0.675 & 0.875 & 1.55 \\
\hline 2 & 1.35 & 2.425 & 3.775 \\
\hline 3 & 1.95 & 4.625 & 6.575 \\
\hline 4 & 2.625 & 7.05 & 9.675 \\
\hline 5 & 3.3 & 9.9 & 13.2 \\
\hline
\end{tabular}

Mehran University Research Journal of Engineering \& Technology, Volume 37, No. 3, July, 2018 [p-ISSN: 0254-7821, e-ISSN: 2413-7219] 
The revised setup is based on optimal utilization of technical human resource for primary duties of first line aviation maintenance that includes but not limited to rectification of aircraft running defects, unscheduled maintenance requirements, documentation/record keeping and staggering of aircraft grounding due to scheduled maintenance requirements. As the revised setup involves lesser number of personnel therefore the amicable application of new scenario would also require revision of procedures involved in secondary affairs that can affect the operations of first line aircraft maintenance management. Following are some important dimensions of impacting factors which requires qualityenhanced actions as per the revised line-maintenance structure:

\subsection{Quality of Hiring Process}

In order to fulfill the requisites for non-licensed cadre in revised model, it is felt that the quality of selection criteria for fresh entrants should be upgraded with a view to select applicant having above-average IQ and aptitude. The candidates must be judged for their level of understanding in regards to the basic philosophies and theories of both-mechanical and electrical engineering. Special attention would be required for hiring profiles and succession planning in order to meet the challenges of the revised model. The candidates must be screened with the set of questions designed to assess their skills for job suitability with special focus to predict their characteristics to perform under team-based, quality-focused environment. The human resource so selected will require lesser time to become proficient in execution of maintenance actions with safety and confidence. For example, if the selected technician has done pre-engineering in his higher secondary education level, then it is expected that he is familiar with the laws of motion, laws of thermodynamics, fluid dynamics and at the same time with the phenomena of Electricity such as ESD effects and causes etc. Hence the entrance tests must include questions related to both the specialties so that the technician, once inducted, could understand the mechanics and dynamics of aircraft systems.

TABLE 5. COST OF PERSONNEL IN REVISED MODEL (COMPARISON)

\begin{tabular}{|c|c|c|c|c|c|c|}
\hline \multicolumn{7}{|c|}{ Results Comparison } \\
\hline \multirow{2}{*}{ Aircraft Type(s) } & \multicolumn{3}{|c|}{ Human Resource (No) } & \multicolumn{3}{|c|}{ Cost Effect (In Mill USD) } \\
\hline & Scenario-I & Scenario -II & Change (\%) & Scenario-I & Scenerio-2 & Change (\%) \\
\hline 1 & 132 & 106 & -66.6 & 4.6 & 1.55 & -66.3 \\
\hline 2 & 264 & 211 & -75 & 9.25 & 3.775 & -59.2 \\
\hline 3 & 396 & 317 & -77.7 & 13.85 & 6.575 & -52.5 \\
\hline 4 & 528 & 422 & -80.1 & 18.5 & 9.675 & -47.7 \\
\hline 5 & 660 & 528 & -81.3 & 23.1 & 13.2 & -42.8 \\
\hline
\end{tabular}

TABLE 6. QUALITY ENHANCEMENT FACTORS

\begin{tabular}{|c|c|c|c|}
\hline No. & Factor/Area of Improvement & $\begin{array}{c}\text { Recommended by } \\
\text { No of Respondents (No) }\end{array}$ & $\begin{array}{c}\text { Recommended by Percentage of } \\
\text { Respondents (\%) }\end{array}$ \\
\hline 1 & Quality of hiring process & 25 & 28.7 \\
\hline 2 & Quality of skill development process & 23 & 26.9 \\
\hline 3 & Quality in maintenance practices & 22 & 25.4 \\
\hline
\end{tabular}

Mehran University Research Journal of Engineering \& Technology, Volume 37, No. 3, July, 2018 [p-ISSN: 0254-7821, e-ISSN: 2413-7219] 


\subsection{Quality of Skill Development Process}

After suitable selection/induction of fresh entrants, the most important aspect is their training and skill development and enhancement. The importance of training and education grows further in the revised setup. Out of the savings made in revised setup, a slight rise in expenditure on skill development process would definitely add value to the professional capabilities of the employees. The organization should transform its course syllabus as per the requisites of revised model whereby the students must be taught all the modules of aircraft systems regardless of the trade specialties. Once the technician qualifies and successfully complete the courses, he/she must be capable enough to understand the basic terminologies and operational phenomena of aircraft systems. The skill development courses must be designed in a way that the course contents must be of highest quality with emphasis on both theoretical as well as the practical application of knowledge. Along with the skill development, the new entrants must also be groomed for the aspects such as quality awareness, interpreting and using data, problem solving, teamwork, importance of customer, zero error tolerance for degree of safety, and accuracy of action required in aviation business. The organization must generate opportunities for the fresh entrants in order to inculcate in them the desired level of professionalism with utmost ethical values because the aviation business is one where even a minutest doubt in actions is un-acceptable. In a nutshell, the revised model asks for above-average professionals with highest quality of knowledge on the aviation system and their operations.

\subsection{Quality in Maintenance Practices}

In order to prevent the organization from human factor related occurrences, the revised management model for first line aircraft fleet demands for highest level of supervision. The situation asks for mental harmony of individuals involved. This harmony could be achieved through improved managerial practices such as introduction of flexi-maintenance concept whereby the worker has the liberty to choose working hours that best suits his schedule. The employees should not be bound to stay at the work place if there is no task to perform. The performance measurement should be based on result-oriented output by the individuals. Although the coercive aspect of management is a part of managerial practices yet it should be restricted to bare minimum. Instead, the workers should be motivated through welfare measures to keep their morale high. The success of organization is as much dependent on loyal and motivated employees as much it depends on the satisfied customers.

\section{CONCLUSION}

From the research work it has been concluded through mathematical study and experimentation that improved quality measures along with synergy concept for human resource utilization can achieve optimal results in aviation business. Quality enhancement in three major areas namely hiring process, skill development process and maintenance practices have major role to play for optimum utilization of human resource assets and hence management should concentrate more on these three quality enhancement areas for better results with lower costs. The results finally achieved show remarkable reduction in overall cost effect while providing first line maintenance support to multi type aircraft fleet. 


\section{ACKNOWLEDGEMENT}

First of all, we would like to thank ALLAH ALMIGHTY for granting us wisdom and courage to carry out research work on such an important aspect of aviation industry. We would like to acknowledge the support of aviation industry people specially those engineers and technicians who are performing first line maintenance on different fleets for their detailed input during our research phase.

\section{REFERENCES}

[1] Papakostas, N., Papachatzakis, P., Xanthakis, V., Mourtzis, D., and Chryssolouris, G., "An Approach to Operational Aircraft Maintenance Planning", Decision Support Systems, Volume 48, pp. 604-612, December, 2009 .

Yan, S., Yang, T.H., and Chen, H.H., "Airline ShortTerm Maintenance Manpower Supply Planning", Transportation Research Part-A, pp. 615-642, October, 2001.

Moudani, W., and Camino, F.M., “A Dynamic Approach for Aircraft Assignment and Maintenance Scheduling by Airlines", Journal of Air Transport Management, Volume 6, pp. 233-237, February, 2000.

Gramopadhye, A.K., and Drury, C.G., "Human Factors in Aviation Maintenance: How We Got to Where We Are",International Journal of Industrial Ergonomics, Volume 26, pp. 125-131, July, 2000.

Kilpia, J., and Vepsalainen, A.P.J., "Pooling of Spare Components between Airlines", Journal of Air Transport Management, Volume 10, pp. 137-146, October, 2004.

Hoffman, P.C., "Fleet Management Issues and Technology Needs", International Journal of Fatigue, Volume 31, pp. 1631-1637, August, 2009.

Masud, A.S.M., Metcalf, P., and Hommertzheim, D., "A Knowledge-Based Model Management System for Aircraft Survivability Analysis", European Journal of Operational Research, Volume 84, pp. 47-59, November, 1995.

[8] Ghobbar, A.A., and Friend, C.H., "The Material Requirements Planning System for Aircraft Maintenance and Inventory Control: A Note", Journal of Air Transport Management, Volume 10, pp. 217-221, March, 2004.
[9] Sodhi, M., "Managing Demand Risk in Tactical Supply Chain Planning for a Global Consumer Electronics Company", Production and Operations Management, Spring, 2005.

[10] Lee, L.H., Chew, E.P., Teng, S., and Chen, Y., "MultiObjective Simulation-Based Evolutionary Algorithm for an Aircraft Spare Parts Allocation Problem", European Journal of Operational Research, Volume 189, pp. 476-491, September, 2008.

[11] Behrens, A., "Managing the Supply Chain Across the Aerospace Life Cycle", Taxal, March, 2010.

[12] Stojkovi, G., Soumis, F., Desrosiers, J., and Solomon, D.M.M., "An Optimization Model for a Real-Time Flight Scheduling Problem", Transportation Research Part-A, Volume 36, pp. 779-788, May, 2002.

[13] Sriram, C., and Haghani, A., "An Optimization Model for Aircraft Maintenance Scheduling and ReAssignment", Transportation Research Part-A, Volume 37, pp. 29-48, September, 2003.

[14] Liang, G.F., Lin, J.T., Hwang, S.L., Wang, E.M., and Patterson, P., "Preventing Human Errors in Aviation Maintenance Using an Online Maintenance Assistance Platform", International Journal of Industrial Ergonomics, pp. 1-12, July, 2010.

[15] Hsu, Y.L., Li, W.C., and Chen, K.W., "Structuring Critical Success Factors of Airline Safety Management System Using a Hybrid Model", Transportation Research Part-E, Volume 46, pp. 222-235, January, 2010.

[16] Janic, M., "An Assessment of Risk and Safety in Civil Aviation", Journal of Air Transport Management, Volume 6, pp. 43-50, November, 2000.

[17] Sarac, A., Batta, R., and Rump, C., "A Branch-and-Price Approach for Operational Aircraft Maintenance Routing”, European Journal of Operational Research, Volume 175, No. 3, pp. 1850-1869, March, 2006.

[18] Tiwari, M., "An Exploration of Supply Chain Management Practices in the Aerospace Industry and in Rolls-Royce", June, 2005. 
[19] Soon, Q., and Udin, Z.M., "Supply Chain Management from the Perspective of Value Chain Flexibility: An Exploratory Study", Journal of Manufacturing Technology Management, Volume 22, No. 4, pp. 506-526, August, 2011
[20] Pleumpirom, Y., and Amornsawadwatana, S., "MultiObjective Optimization of Aircraft Maintenance in Thailand Using Goal Programming: A Decision-Support Model", School of Engineering, University of the Thai Chamber of Commerce, 10400, Thailand, April, 2012. 